This item was submitted to Loughborough's Research Repository by the author.

Items in Figshare are protected by copyright, with all rights reserved, unless otherwise indicated.

\title{
Establishing the zero-carbon performance of compact urban dwellings
}

PLEASE CITE THE PUBLISHED VERSION

http://dx.doi.org/10.1080/19401493.2012.724086

\section{PUBLISHER}

Taylor and Francis Ltd @ International Building Performance Simulation Association (IBPSA)

\section{VERSION}

AM (Accepted Manuscript)

\section{LICENCE}

CC BY-NC-ND 4.0

\section{REPOSITORY RECORD}

Steijger, L.A., Richard A. Buswell, Vincent Smedley, Steven K. Firth, and Paul Rowley. 2019. "Establishing the Zero-carbon Performance of Compact Urban Dwellings". figshare. https://hdl.handle.net/2134/13048. 
This item was submitted to Loughborough's Institutional Repository (https://dspace.lboro.ac.uk/) by the author and is made available under the following Creative Commons Licence conditions.

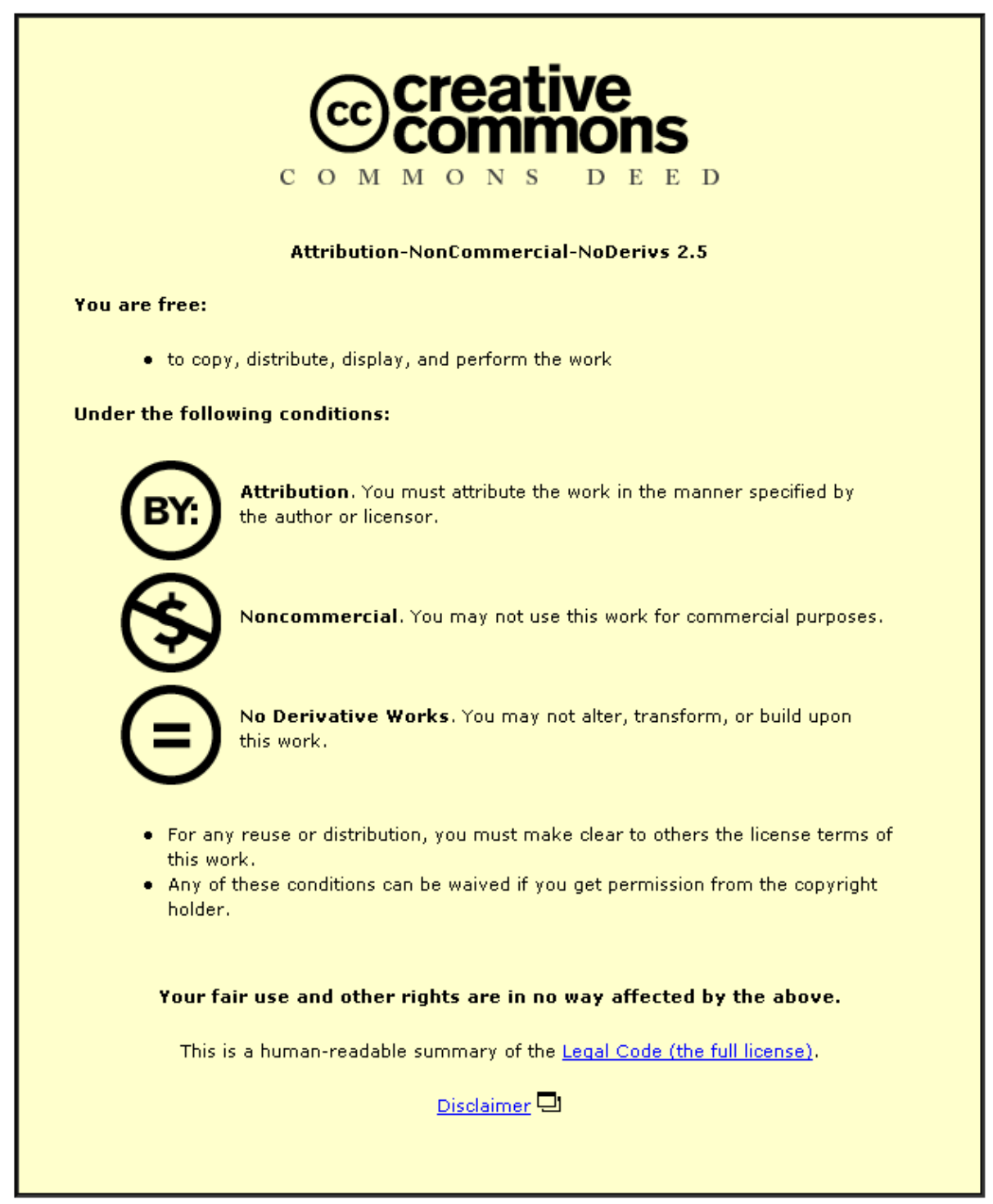

For the full text of this licence, please go to: http://creativecommons.org/licenses/by-nc-nd/2.5/ 


\title{
Establishing the zero-carbon performance of compact urban dwellings
}

\author{
L.A. Steijger ${ }^{1}$, R. A. Buswell ${ }^{2}$, Vincent Smedley ${ }^{3}$, S.K. Firth ${ }^{2}$, P. Rowley ${ }^{1}$
}

${ }^{I}$ Centre for Renewable Energy Systems Technology, University of Loughborough, UK

${ }^{2}$ Department of Civil and Building Engineering, University of Loughborough, UK ${ }^{3}$ East Midlands Renewable Energy Ltd, Derby, UK

Laurence A. Steijger

9 The Hamlet

South Normanton

DE55 2JA Derbyshire

United Kingdom

Laurence@silvercrestec.com 


\section{Establishing the zero-carbon performance of compact urban dwellings}

This paper presents an analysis of the zero-carbon performance of a case study building which is representative of a growing number of new buildings that are being built on redevelopment sites in inner-city areas in the UK. Compact urban dwellings are apartment style buildings with a floor area of $\sim 50 \mathrm{~m}^{2}$ per dwelling, often based over two floors. The constraints of this type of building on achieving zero-carbon performance in the context of the Code for Sustainable Homes is discussed and the shortcomings of the code are demonstrated in terms of the target heat and electricity demand targets for the design of the building systems. A graphical representation of the simulation results is used to present the findings and demonstrates that zero-carbon operation of the building is not possible.

Keywords: zero-carbon; energy generation systems; CHP; solar; compact urban dwelling; system integration

\section{Introduction}

It is widely accepted that climate change is a serious and urgent issue that needs to be addressed by reducing the level of GreenHouse Gas (GHG) production globally (Stern 2007). The Intergovernmental Panel on Climate Change (IPCC)'s Fourth Assessment Report (2007) confirms that the primary concern is that greenhouse gas emissions from human activity have risen "by 70\% between 1970 and 2004". Following the Royal Commission on Environmental Pollution (RCEP) report (2000) the UK government committed to an $80 \%$ reduction in $\mathrm{CO}_{2}$ emissions by 2050 , enforcing changes through legislation. Meeting this emissions goal of the UK can only be achieved through setting and achieving strict targets in all energy-consuming sectors (McManus et al. 2010), and as over $27 \%$ of UK's $\mathrm{CO}_{2}$ emissions come from the energy used to heat, light and run homes (Department for Communities and Local Government 2007), it is vital to ensure 
that higher sustainability performance standards are integrated within the design of new homes.

The UK government has introduced the Code for Sustainable Homes (CSH) to drive a step-change in sustainable home building practice (Department for Communities and Local Government 2006). The CSH is an environmental assessment method for rating and certifying the performance of new homes and is a UK government owned, national standard. The CSH covers nine categories of sustainable design, of which 6 are mandatory (energy and $\mathrm{CO}_{2}$ emissions, water, materials, surface water run-off, waste and health and well-being) and 3 are flexible (pollution, management during build and occupation and ecology). To obtain the highest level of the code, level 6, net emissions of carbon dioxide must be zero. With the exception of water consumption, the objectives are flexible and are rated to a point scheme, where points are accumulated in each category and summed to calculate a percentage of the target value. The required percentage to achieve level 6 is $90 \%$.

By 2016 all new homes built in the UK must meet these criteria of the CSH (Department for Communities and Local Government 2008), requiring them to be "zero carbon" (Energy Saving Trust 2008). As a result, to meet the energy demand, zero carbon energy (used for space heating, hot water and power for lighting and electrical appliances) must be generated in or near the building to offset any fossil or fossilgenerated fuels imported into the home, so that over a year, the net carbon emissions are zero (McManus et al. 2010).

To compound the challenges of compliance with these requirements, the UK housing market is under pressure from a rising population and there is a shift towards the construction of smaller dwellings (McManus et al. 2010). It is projected that between 2004 and 2016 there will also be an extra 1.85 million single person 
households in England alone, with these figures contributing to a total increase of 2.8 million new households by this date (Department for Communities and Local Government 2007). Banfill and Peacock (2007) state that the trend towards inward migration is resulting in new homes being built on brown field sites in towns and cities, where space is limited. The lack of space for buildings on such sites tends to produce workable designs of smaller, apartment based dwellings, which is different from single property living in a house on its own land which is common throughout much of the UK. These new built homes, or compact urban dwellings, often have a living space of around $50 \mathrm{~m}^{2}$ in either one or two stories with a likely occupation of either one or two people. The CSH stipulates that all energy must be generated on-site and hence the limited space for the installation of energy generation plant, heat storage equipment and bio-fuel storage presents a major challenge.

The shape of the site and planning restrictions often constrain the orientation of the building and the roof height, which has a direct impact on the available solar energy received by the building. The availability of solar radiation in winter in particular, can be severely restricted due to close proximity of existing structures that can cause shading on the roof, which in most cases is the only surface available for collecting solar energy. In compact urban dwellings, this problem is exacerbated because a living space of $\sim 50 \mathrm{~m}^{2}$ over two stories results in a maximum roof area of $25 \mathrm{~m}^{2}$ per dwelling; multi-storey flats have less than this.

This paper investigates the implications of the practical constraints of delivering a real building to code level 6 performance standards. The paper focuses on the selection and evaluation of suitable building energy generation system options under engineering and installation constraints for a case study building. A number of workable 
generation options for the building are established and the performance of each option compared in terms of the net annual $\mathrm{CO}_{2}$ production.

\section{CSH level 6 building and system design: Practical constraints}

In the CSH (Department for Communities and Local Government 2006) the highest rating is level 6 and the code states that for this status to be awarded to a building it needs to be '... a completely zero carbon home (i.e. zero net emissions of carbon dioxide (CO2) from all energy use in the home)...'. The challenge for the designer is that there is no reference to the energy consumption from the occupant driven loads that should be attained and so designing systems to deliver zero carbon performance in use in order to achieve this standard is challenging and represents a significant omission in the document. As the standard refers to a net emission, generation of the energy does not have to occur simultaneously to the consumption, e.g. if the electricity is generated and fed into the grid, and consumed at a later stage from the grid, it is still accepted to be zero-carbon.

For code level 5, the next performance level down the scale, the energy performance is stated to be $100 \%$ better than the 2006 Building regulations Part L (Office of the deputy Prime Minister), which is '...zero emissions in relation to Building Regulations issues (i.e. zero emissions from heating, hot water, ventilation and lighting)...' . From this, it can be inferred that in order to comply with code level 6 , apart from the requirements for code level 5 for energy used for space heating, ventilation, water heating, and lighting, occupant consumption of small power and ancillary loads such pumps and controls must be also generated through the use of zero-carbon technologies.

Zero carbon housing has been shown to be possible by reducing the demand for 
energy in combination with micro generation (Keirstead 2007). The largest energy use in dwellings in the UK is said to be space heating. Mahdavi and Doppelbauer (2010) provide information on passive house design and the influence of high insulation and low ventilation losses on the indoor environment. They conclude that space heating requirements can be reduced to $10 \mathrm{~W} / \mathrm{m}^{2}$ by using effective insulation, low ventilation losses through air tight building and ventilation with heat recovery and by maximising winter solar gain. Wall constructions with a U-value of less than $0.15 \mathrm{~W} / \mathrm{m}^{2} \mathrm{~K}$ and windows with a U-value of less than $1.0 \mathrm{~W} / \mathrm{m}^{2} \mathrm{~K}$ are becoming viable options in the building industry and hence designing to the highest thermal insulation standards is a significant step towards achieving a zero-carbon building.

Minimising infiltration losses by assuring high standards of construction and using systems such as Insulated Concrete Form (ICF) is important coupled with heat recovery in the ventilation system which can reduce typical ventilation losses by up to 90\% (Segen 2006). The inclusion of the mechanical ventilation and the subsequent reduction in heat demand is a necessary trade-off with additional electricity demand. The quantity of Domestic Hot Water (DHW) to supply is not specified in the $\mathrm{CSH}$, although a limit of 80litres/person/day of (the sum of hot and cold) potable water is required for the application of code level 6 . This is achieved by a combination of water saving faucets, smaller baths, etc. and the use of grey water.

The combustion of biomass in boilers or combined heat and power (CHP) plant is a low-carbon alternative to the preferred zero-carbon heat that can be generated either by the application of solar photovoltaic arrays (PV) or wind turbines used to generate electricity to drive heat pumps (HP), or by solar thermal collectors (STC). The only space available for solar collection is the roof where approximately $25 \mathrm{~m}^{2}$ is available for solar collection per home. Practical field tests for an optimised system with 
sufficient thermal storage show an annual yield in the UK of 1000 to $1500 \mathrm{MJ} / \mathrm{m}^{2}$ year (Martin and Watson 2001) on a $30^{\circ}$ pitched roof due south. Lower pitched roofs combined with limited storage will show a lower yield, especially in winter. With a DHW requirement of approximately $5500 \mathrm{MJ} /$ year $(1528 \mathrm{kWh} /$ year) $20 \%$ of the roof space should be sufficient to cover the demand for DHW.

To fulfil the electrical energy requirement for zero carbon dwellings, all the electricity consumed by the building has to be generated without carbon emissions. Allen and Hammond (2010) found in their analysis that the combination of a microwind turbine and a solar PV system can completely displace the need for electricity from the grid. Wind generation, however, has also been shown to cause noise problems and have a low yield in urban locations (Watson et al. 2008). Numerous papers have been published on the yield of PV, for example: Allen and Hammond (2010), Ren et al. (2010), James et al. (2010), Bahaj and James (2007); and with a specific focus on urban environments by Steemers (2003), Tian et al. (2007) and Compagnon (2004). Huld et al. (2008) show that a typical yield of a PV system in the UK is around $750-800 \mathrm{kWh} / \mathrm{year}$ per kWp-installed power. This yield may meet the electricity demand for a compact urban home, but it competes for roof space with the solar thermal energy collection and so practically the demand for heat and power is unlikely to be met from solar collection from the roof alone.

The CSH states that code level 6 can be achieved by '...Using low and zero carbon technologies such as solar thermal panels, biomass boilers, wind turbines, and combined heat and power systems (CHP). It would mean for example that energy taken from the national grid would have to be replaced by low or zero carbon generated energy, so that over a year the net emissions were zero. ...'. The conversion factors paper from the Department for Environment, Food and Rural Affairs (2011), however, 
states that all bio-fuels generate a certain amount of carbon emissions and are therefore not strictly speaking carbon neutral, but have lower $\mathrm{CO}_{2}$ emissions than fossil fuels. To comply with the code level 6 standards, any $\mathrm{CO}_{2}$ produced by the combustion of biofuels would still need to be offset such that the net emissions are zero over a year.

Biomass fuels can be obtained in (liquefied) biogas, liquid (waste vegetable oil) or solid (wood, elephant grass) forms. Space is at a premium in the urban environment, so the fuel with highest energy density is likely to be favoured. Solid fuels such as wood have an energy density of $2.5 \mathrm{MWh} / \mathrm{m}^{3}$, liquid gas such as LPG $7.0 \mathrm{MWh} / \mathrm{m}^{3}$ and waste vegetable oil approximately $10.0 \mathrm{MWh} / \mathrm{m}^{3}$ (BINAS 1998), making this a likely candidate fuel. In addition, there is a distribution network available, no requirement for pressurised storage of vegetable oil and the conversion to heat and/or electricity through micro-CHP is well established. Bio gas is in limited supply with no distribution network hence, if there is sufficient biogas available with a well established distribution network, this might become an option for generation of zero-carbon thermal and electrical energy. Solid bio fuels are available on the market; however, small solid bio fuel plant can only convert this energy into thermal energy, leaving out the flexibility to generate electrical energy.

The $\mathrm{CSH}$ does not give any reference to the expected energy consumption of dwellings through lighting and small power, although credits are earned for the use of efficient appliances and lighting systems. A key challenge in designing a building to deliver zero-carbon performance is understanding the range of consumption that can reasonably be expected in-use and the idea of a 'performance envelope' has been proposed (Steijger et al, 2012). This is particularly important since a study by Richardson et al. (2010) showed a tenfold difference between the lowest and highest electricity usage in comparable dwellings, which has a significant impact on the 
determination of the balance of the generation technologies for a specific building. Achieving zero-carbon in practice can only be achieved if realistic assumptions are made with regard to the demand. Once a building and its systems are complete the only recourse for a building that doesn't operate at zero-carbon is to reduce the energy demand in-use which is challenging since this is only likely to be achieved through long term education of the occupants (Bahaj and James 2007, Keirstead 2007).

In summary, achieving the CSH level 6 in compact urban dwellings is challenging principally due to the constraints on building orientation, height, roof area and pitch and the limited space for the generation equipment, thermal and fuel storage. The problem is compounded for the designer by the lack of benchmarks and targets to indicate realistic occupant led demand. These include:

- internal air temperature, affecting the space heating load through variations in control and thermostat settings;

- hot water demand and consumption profiles, although minimised with efficient devices, this is still largely dependant on the occupant; and

- lighting and small power, again minimised through efficient devices, but usage still led by the occupant.

Apart from the obvious contribution to the UK government's $\mathrm{CO}_{2}$ reduction targets, the CSH highlights the benefit of lower energy bills in rated properties and this is a key selling point property developers use to attract customers. While some degree of occupant education on effective use of the systems with in a zero-carbon property is necessary, obtaining the correct balance of the provision of electricity and heat (in particular) while placing practical limits on the supply is critical to whether the building will be judged successful by the occupants. This lack of guidance hampers the 
designers job of determining sensible values on which to base the analysis of the mix of zero and low carbon generation technologies.

The rest of this paper focuses on a real compact urban housing development that was constructed in 2011. The building is introduced and the assumptions in the analysis are discussed. These lead to an analysis of the $\mathrm{CO}_{2}$ emissions performance of various mixes of generation technologies.

\section{Description of the case study building}

The SHINE-ZC building in Derby (UK) comprises of 9 adjacent compact urban dwellings; six 2-storey houses and a 3-storey block containing three flats and a shared staircase. Each dwelling has a living space of approximately $50 \mathrm{~m}^{2}$. The total internal volume is $1326 \mathrm{~m}^{3}$. The dwellings are adjoined as shown in Figure 1 and Figure 2.

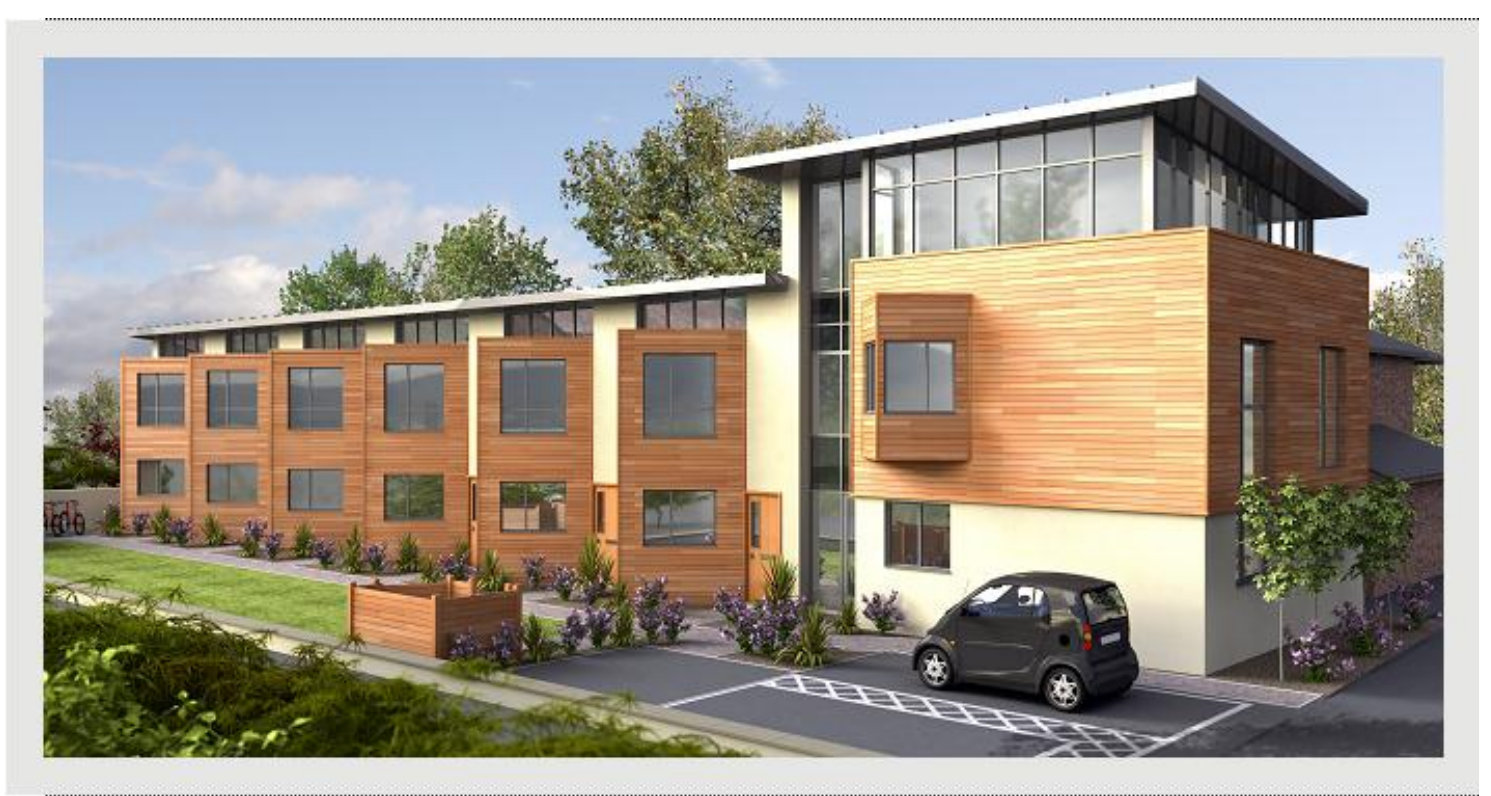

Figure 1: Render of the development (Simon Foote Architects 2008). 


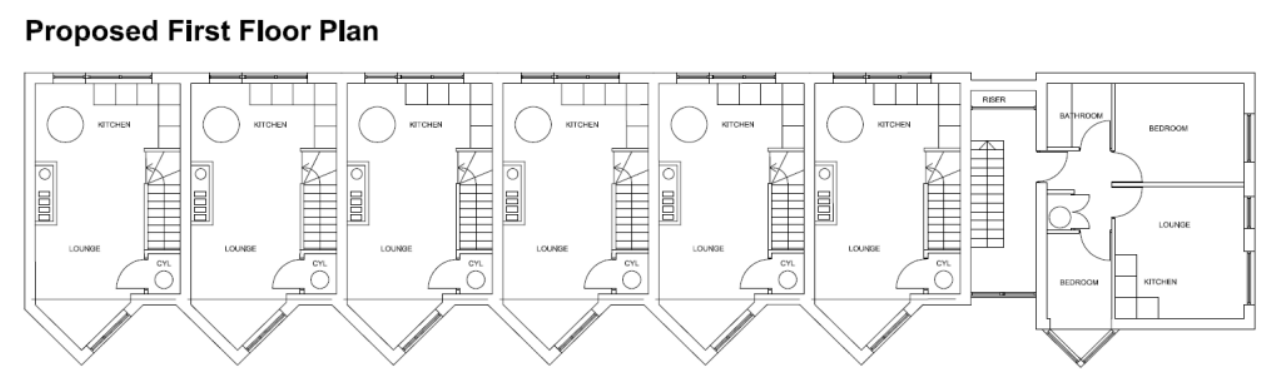

Proposed Ground Floor Plan

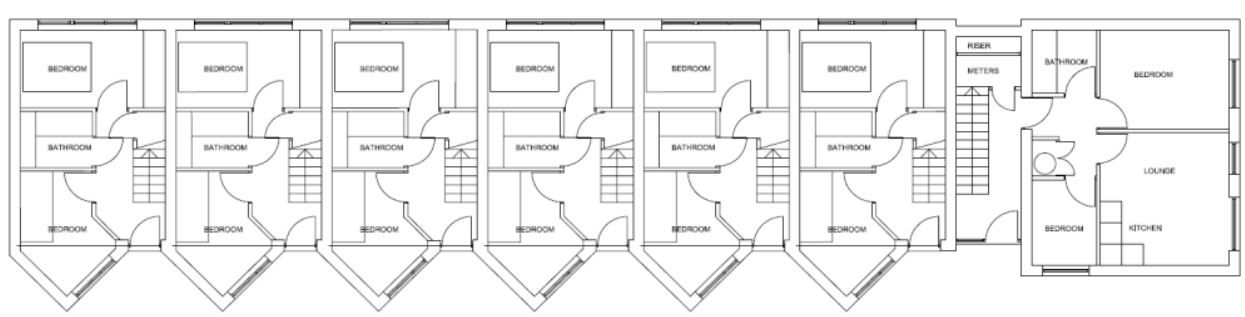

Figure 2: Floor plans of the dwellings (Simon Foote Architects 2008).

The front of the building faces approximately north, dictated by the shape of the site. The roof area is split in two levels; approx. $160 \mathrm{~m}^{2}$ on the houses and $70 \mathrm{~m}^{2}$ on top of the flats. Due to planning height restrictions the $230 \mathrm{~m}^{2}$ roof faces south with a 6 degree slope, rather than the $40^{\circ}$ south facing slope that is deemed ideal in terms of solar collector yield for this latitude (Energy Saving Trust 2004).

The wall material is constructed with Integrated Concrete wall Form (ICF), a layered and highly insulating construction comprising of 150mm of expanded polystyrene, $150 \mathrm{~mm}$ structural concrete, another $75 \mathrm{~mm}$ of styrene and the internal surface is plasterboard with a skim coat $15 \mathrm{~mm}$ thick. The external surface has either $10 \mathrm{~mm}$ thick wooden cladding or $10 \mathrm{~mm}$ render, depending on the location on the building (see Figure 1). The resultant $\mathrm{U}$-value is $\sim 0.12 \mathrm{~W} / \mathrm{m}^{2} \mathrm{~K}$. The construction quality was closely managed and on-site air permeability tests estimated air permeability less than 0.35 air exchanges per hour for each dwelling during operation. The windows are triple glazed, with a U-value of $1 \mathrm{~W} / \mathrm{m}^{2} \mathrm{~K}$. The solar gain in winter is minimal due to the shading of adjacent buildings, but the solar gain needs to be limited to prevent 
overheating in the summer as the internal gains are expected to provide enough heat to maintain the desired space conditions for all but the coldest parts of the year. The solar gain is limited by placing the majority of the windows on the north side of the building, whilst south facing windows are fully shaded in summer by an overhanging roof ridge and adjacent buildings.

The building is designed to have warmer living spaces and cooler bedrooms by placing the living space on the first floor and the bedrooms and bathrooms on the ground floor. An overview of the key design parameters for the building is given in Table 1.

A critical part of the building is the thermal store which is required to buffer the heat produced from the generation plant and the demand for heat. In this building the configuration of the thermal store is a water tank that is heated through independent circuits serving each generation device. The DHW water is drawn directly from the tank and the space heating circuit extracts heat from the tank via a coil of copper piping acting as a heat exchanger. Space heating is provided through radiators, each with a thermostatic radiator valve (TRV) for individual room air temperature control. The space heating in each dwelling is also controlled by a central thermostat located in the hallway of that dwelling which switches a circulation pump to circulate water heated by the thermal store through the radiators. Figure 3 depicts the arrangement of the heat and electricity supply for the building.

Table 1: Key parameters of the building.

\begin{tabular}{cccccc}
\hline End & Middle & Bottom & Middle & Top flat \\
house & houses & flat & flat & \\
\hline
\end{tabular}




\begin{tabular}{|c|c|c|c|c|c|}
\hline Number of units & 1 & 5 & 1 & 1 & 1 \\
\hline Floor area $\left(\mathrm{m}^{2}\right)$ & 55 & 55 & 42 & 44 & 46 \\
\hline Volume $\left(\mathrm{m}^{3}\right)$ & 140 & 140 & 105 & 110 & 115 \\
\hline External wall area $\left(\mathrm{m}^{2}\right)$ & 75 & 45 & 47.5 & 50 & 52.5 \\
\hline Window area $\left(\mathrm{m}^{2}\right)$ & 8.5 & 8.5 & 5.5 & 6.5 & 6.5 \\
\hline Roof area $\left(\mathrm{m}^{2}\right)$ & 30 & 30 & - & - & 70 \\
\hline Ventilation rate (exch./hr) & 0.53 & 0.53 & 0.93 & 0.93 & 0.93 \\
\hline Heat loss fabric $(\mathrm{W} / \mathrm{K})$ & 21 & 18 & 13 & 11 & 15 \\
\hline Ventilation heat loss $(\mathrm{W} / \mathrm{K})$ & 17 & 17 & 17 & 17 & 17 \\
\hline
\end{tabular}

The capacity and configuration of the thermal store has a significant impact on the performance and operational characteristics of the generation equipment. In this building individual thermal stores provide the space heating and DHW capacity for each dwelling. This was a decision made early in the design since it has an impact on the provision of volume required to house it and hence on the architectural layout of the building. The decision to go for a number of separate stores over a single store was made based on the concern for lags in the supply of hot water that has been shown to be an issue with larger centralised systems (Knoll and Wagenaar, 1994). 


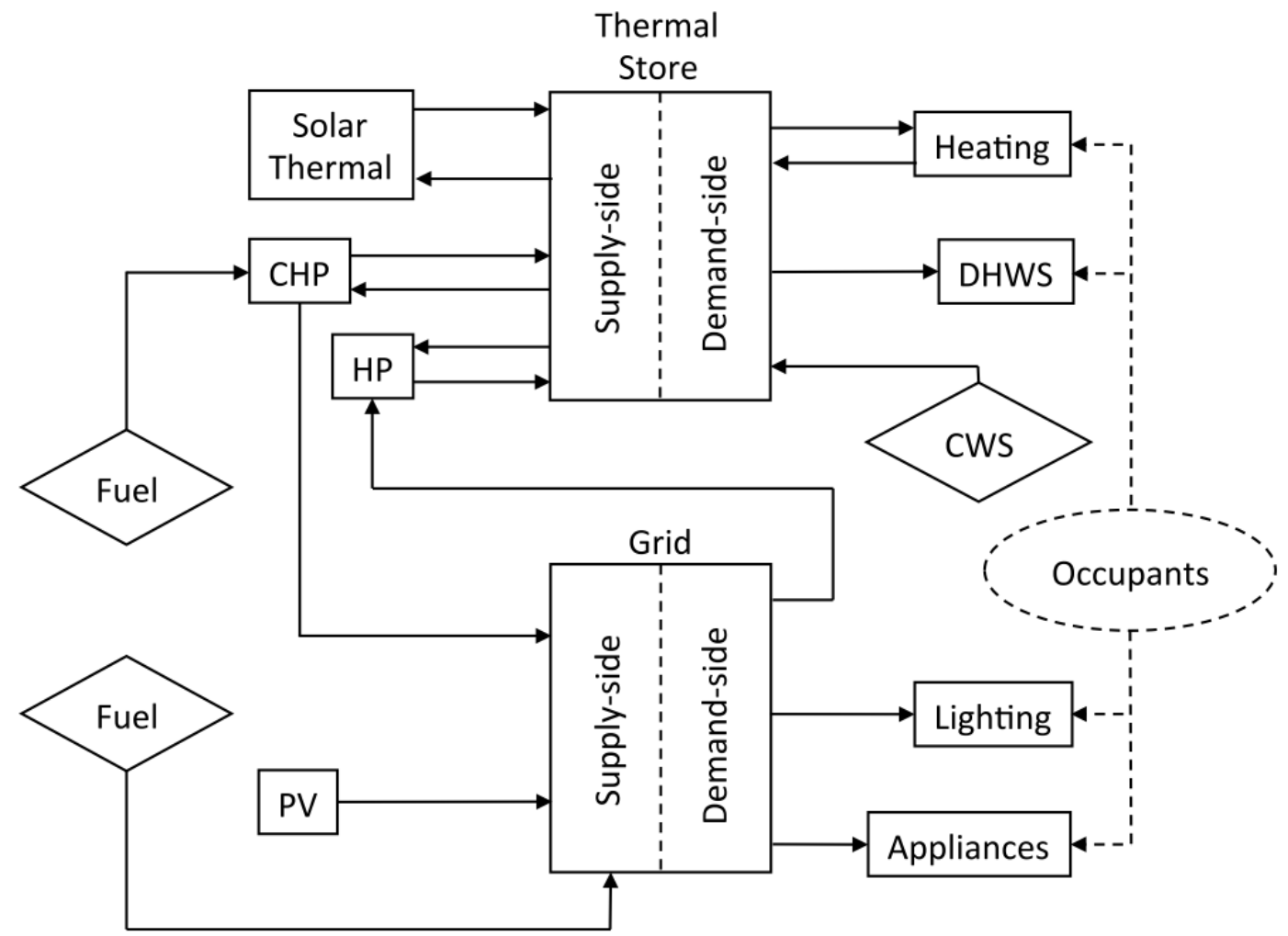

Figure 3: the arrangement of the building heat and electricity generation options.

\section{Modelling assumptions, issues and constraints}

TRNSYS Version 16.01.003 (Klein et al, 2007) was used to investigate the influence of heat and electricity demands on the on-site zero carbon generation performance of a number of generation options. Each of the six houses was divided into two zones per house, one upstairs and one downstairs. Each of the flats and the staircase was modelled as a single zone. There are a number of stages to the analysis discussed in this section:

- modelling the building fabric and systems;

- selecting the appropriate capacities of the plant;

- establishing the demand profiles as inputs to the simulation; and,

- handling the interdependencies of heating and electricity generation and demand. 
The detail of the characteristics of the occupancy, heating, DHW supply, lighting and small power use for each dwelling used in the analysis is important. Since the CSH does not give any limits or benchmarks to the consumption of energy, the design of the appropriate generation systems is challenging and this is a significant omission in the code. Therefore the UK BREDEM standard methodology (Anderson et al, 2001) was used to set the operating points. The analysis presented here is based on a pragmatic approach to establish the simulation input to gain insight into the problem, before applying full dynamic simulation. Using more detailed representations of these inputs and including these into the dynamic modelling of the systems and their control might generate a better estimate of the in-use performance, but is this beyond the scope of this paper.

\subsection{Occupancy}

Anderson et al. (2001) describe occupancy during the daytime as 7:00 to 9:00 and 16:00 to 23:00 hours. The heat gain for one person seated at rest is added to the living area of the dwelling (the top floor in the houses). During the night (23:00 till 7:00) the internal heat gain is calculated as one person's heat gain (seated at rest, (CIBSE 1986)) added to the bedroom (the bottom floor in the houses). The dwelling is not occupied from 9:00 until 16:00 hrs.

\subsection{Infiltration, Ventilation and Air movement}

Infiltration was considered to be small $(0.35 \mathrm{ACH})$. Ventilation is provided by a mechanical ventilation and heat recovery (MVHR) unit. For purpose of assessing the heat losses by the MVHR, ventilation rate is reduced by the efficiency using the manufacturer's performance benchmark data as described by Taylor et al. (2010) "the thermal effects of ventilation heat recovery can be simulated precisely by reducing the 
ventilation rate by the proportion of heat recovered". The ventilation rate is as required by the UK building regulations which is 17litres/second/dwelling (Office of the Deputy Prime Minister 2006). The heat recovery rate is specified to be $90 \%$ (Segen, 2006) In summer the MHVR will run to provide ventilation. When the room air temperature is above $24^{\circ} \mathrm{C}$ (maximum acceptable temperature according to the CIBSE guide 1985), the extract air bypasses the heat exchanger. It switches the heat recovery on again when the temperature drops below $22^{\circ} \mathrm{C}$. A lower temperature is not possible as the reference temperature for heating is set to $21^{\circ} \mathrm{C}$ according to the BREDEM method (Anderson et all, 2001). The electrical power used to drive the fan and the heat generated by the heat recovery are added to the internal gains according to the BREDEM method.

\subsection{Electricity demand and electrical internal gain}

Since the CSH does not specify the electrical demands and the $\mathrm{CO}_{2}$ consumption is based on a net-annual value, the BREDEM model (Anderson et al. 2001) is used to estimate the yearly consumption; $2288 \mathrm{kWh}$ per dwelling. This approach does not cover the full performance envelope (Steijger et al, 2012) but does give a point to which a comparison of systems can be based. This value represents the total energy requirement including cooking, electrical lighting, white goods and portable equipment for the complete building. A base load of $75 \mathrm{~W}$ was estimated for the MHVR unit and electricity required for the fridge-freezer. Working backwards from the target of $2288 \mathrm{kWh}$, subtracting the base load of $75 \mathrm{~W}$ running 24 hours, 365 days of the year, leaves a load of $496 \mathrm{~W}$ during occupied hours, taken to be 07:00 until 09:00 and 16:00 until 23:00. 75\% of the load is assumed to be consumed in the living area (first floor). The base load is $25 \%$ lower than the base load as established by Yao and Steemers (2005) and the assumption was made due to the higher efficiency of the appliances and lighting. Seasonal variations were not considered as stated in the BREDEM model and 
apart from the energy consumed in extract fans, internal heat gain to each apartment is equal to the electricity used for appliances and lighting together with $90 \%$ of the energy required for cooking (Anderson et al, 2001). More elaborate load profiles are available, e.g. from Richardson et al, (2010) but the influence of these on the space heating, due to the time constants involved, are limited. Hence a simple load profile was adequate for this study.

\subsection{Heating set-points, control and scheduling}

The code for sustainable homes does not define the internal comfort settings for the dwellings. Therefore the BREDEM temperature settings have been used (Anderson et al, 2001). The default space heating setting is $15^{\circ} \mathrm{C}$ during the night (23:00 until 7:00 hours) and non-occupied hours (9:00 until 16:00 hours); and $21^{\circ} \mathrm{C}$ during the occupied hours (7:00 until 9:00 and 16:00 until 23:00 hours). The space heating input to the living spaces are calculated from the radiator models described by Knoll and Wagenaar (1994). The radiator control time constants determined the time step for the simulation, which was set at 1 minute.

\subsection{DHW storage, draw off and scheduling}

The thermal storage is provided by a water tank in each dwelling. These have to be large enough to provide one day of energy for space heating and DHW and small enough to fit in the limited dwelling space. Practical limitations on the size of the thermal energy storage require a larger temperature fluctuation in the tank to enable sufficient diurnal thermal energy storage. The CHP and flat plate solar thermal collectors can provide high temperature thermal energy (albeit for the solar thermal collectors with a dramatic efficiency drop) up to $95^{\circ} \mathrm{C}$ to prevent boiling of the water, so to store this energy this temperature is the upper limit. No more thermal energy can 
be stored if this temperature is reached, and therefore the thermal energy provided by the CHP or solar thermal is wasted. Given that the UK DHW supply temperatures are typically $48^{\circ} \mathrm{C}$ or above, the thermal stores are taken to be able to supply no useful heat if the bulk water temperature drops below $50^{\circ} \mathrm{C}$. A 315 litre tank per dwelling can provide a full day's heating and hot water demand in the UK Midlands $99 \%$ of the time under standard CIBSE (1986) usage levels if the bulk temperature in the tank is fluctuating with $45^{\circ} \mathrm{C}$. The assumption is that the majority of this water is used for personal hygiene and therefore has a temperature of $40^{\circ} \mathrm{C}$ at the draw-off points. The cold water supply is assumed to be $10^{\circ} \mathrm{C}$ and mixed with the water from the tank to supply at $40^{\circ} \mathrm{C}$ at the required flow rate. According the health and safety executive (2009), to avoid legionella hot water should be stored above $60^{\circ} \mathrm{C}$ and transported above $50{ }^{\circ} \mathrm{C}$. Using a coil in the tank for heating the DHW avoids the storage problem (less than 1 litre is stored) and the minimum temperature setting in the tank ensures that the transportation temperature is met.

The CSH requires that for a level 6 dwelling the potable water consumption must be less than 80litres/day/person. The dwellings are considered here to be single occupancy and since the DHW system uses potable water it is assumed for the sake of capacity sizing and heat supply that the whole 80 litres is drawn off as hot water each day.

The BREDEM calculations use the same water volume, but it does not suggest a water draw-off pattern. The toilets and washing machine will use gray water. It is also assumed that half of the domestic hot water is used in the morning (between 7:00 and 8:00) and half in the evening (between 18:00 and 19:00). 


\subsection{Heat and electricity generation options}

Solar thermal collectors, photovoltaic panels, air-source heat pumps and a bio-fuelled, micro-CHP where considered in this analysis. Watson et al (2008) stated that wind generation has a very limited yield in an urban setting and bio-mass boilers were not considered in this particular case, preference being given to micro-CHP since it generates electricity as well as heat. Ground source heat pumps were also not considered because the available area for horizontal evaporator coil was limited and the commercial viability of installing vertically drilled systems was prohibitive.

If the most common type of PV array (crystalline silicon) is used, Bayod-Rújula et al (2010) show that around $9 \mathrm{~m}^{2}$ of roof space is required to install $1 \mathrm{kWp}$ of PV panels. With $230 \mathrm{~m}^{2}$ of roof space, a maximum installation of approximately $25 \mathrm{kWp}$ can be installed. TRNSYS standard library type $194 \mathrm{~b}$ with inverter is used to determine the yield of the photo-voltaic array.

There is a range of heat to power ratios for CHP from 10:1 (Whispergen, 2010) to 2:1 (Baxi Dachs mini CHP, 2010). A small diesel CHP, however, can reach a 1.5:1 heat to electricity ratio (Tipkoetter BioGenio, 2010). Additional thermal losses with the operation of these small CHP can be high (30\% is not uncommon). The total efficiency of the CHP is assumed to be $35 \%$ electrical output, $35 \%$ effective thermal output, $30 \%$ thermal losses and hence a limiting case of 1:1 heat to electricity has been taken here. With a typical thermal time constant of a CHP of three minutes (running under full load immediate after start, shortening the warming up) and generally if the CHP is started once a day and usually runs un-modulated for longer than two hours to deliver the heat to the 9 thermal stores $\left(2.8 \mathrm{~m}^{3}\right.$ water), the run time is much larger ( $>50$ times) than the start-up time and so the start-up and shut down time constants have been neglected. The store capacity should be sufficient to deliver the thermal energy whilst only be charged once a day; more frequent charging will have a negative effect on the overall heat 
delivery of the CHP. As we do not have the exact losses as relation to the running temperature, the complexity of the control and accurate modelling of all the pipe work in the dwelling, we assumed a relative high initial thermal loss to accommodate this variation i.e. a worst case scenario, which is sufficient to meet the objective of this paper.

Heat can also be generated by the solar thermal array. The solar thermal panels are modelled using the theoretical flat plate collectors, type 73 based on a HottelWhiller steady state model. One of the main parameters affecting the yield of the STC's is the temperature of the fluid entering the collector, coming from the bottom of tank with the lowest temperature. The higher this inlet temperature, the lower the yield. Solar thermal energy is transferred from the collector into the tank if at least one of the tanks has a sufficiently low temperature, measured at the bottom of each tank. No heat is added to the tanks if the tanks are completely charged and the heat is wasted, resulting in a lower yield of the solar thermal system.

Cabrol and Rowley (2011) showed that heat pumps can be effective in low carbon dwellings; hence heat pumps are used as an alternative way to heat up the storage tanks. The power consumption and the Coefficient of Performance (COP) was modelled for a standard heat pump with a rated COP of 3.5 and a high performance heat pump with a rated COP of 4.3 under standard conditions described in Steijger et al, (2010) and Sparn et al. (2011). The maximum temperature the heat pump can deliver is $65^{\circ} \mathrm{C}$, hence the heat pump switches off when the bottom node in each of the storage tanks reach this temperature. The electrical power consumed by the heat pumps needs to be offset by either the PV array or micro-CHP. The start up time constant for an air source heat pump is approximately 40 seconds (Steijger et al., 2010) and since the time to charge the thermal stores is very much larger (larger than 2000 seconds) typically the 
unit would be expected to run for 30 minutes or more and hence the start up dynamics have been neglected in this analysis.

\section{Building demand characteristics}

There are a number of dependencies on the generation of heat and power: the microCHP generates both heat and electricity simultaneously and the ratio is a fixed characteristic of the equipment; the HP provides heat, but must be supplied with electricity; and the PV and STC compete for roof space and hence affect the ratio of zero-carbon heat and electricity production that can be achieved. Lastly the heat gain generated by the consumption of electricity in the dwellings affects the heat demand for space heating and specifying the system capacities and operational parameters is challenging. In addition, where more than one renewable option is applied, the interdependency of the demand for electricity and heat coupled with the interdependency of generation complicates the issue.

Figure 4 depicts the total electrical, DHW and space heating demand for each month for a typical year. The total annual energy demand is $19.2 \mathrm{MWh}$ for the whole building. Approximately one third of the electrical demand is for cooking, 15.3MWh of DHW demand and just 3.8MWh for space heating. 


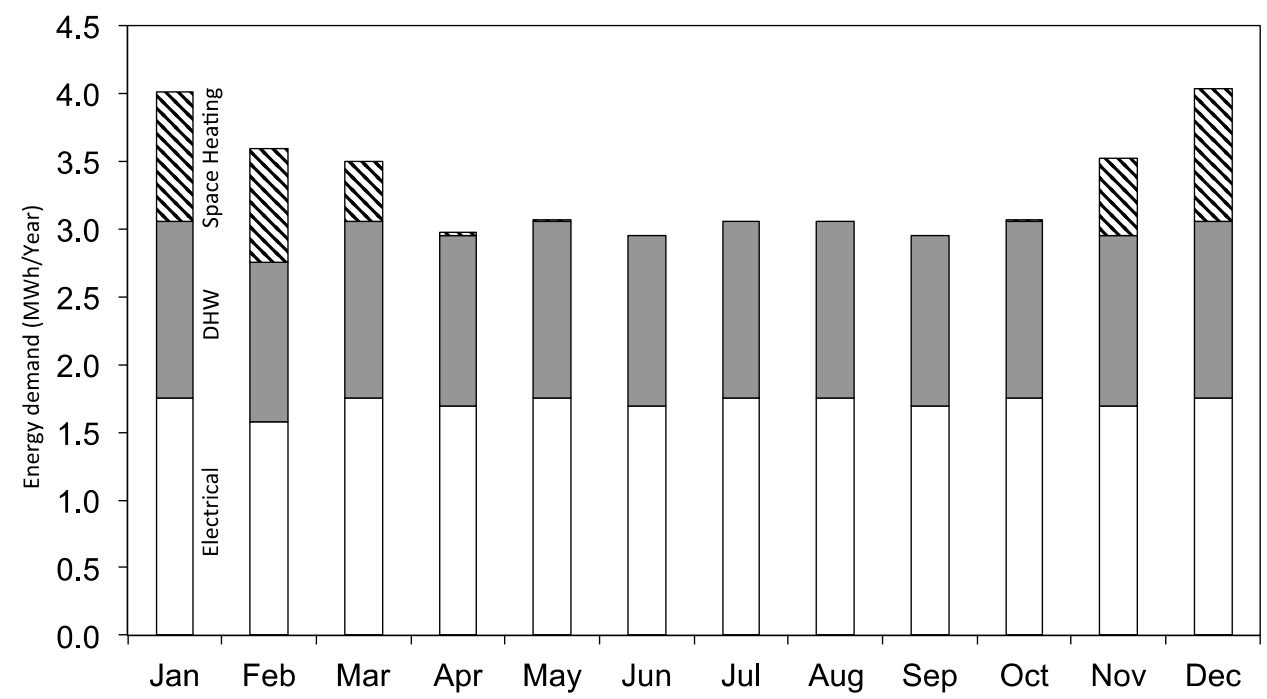

Figure 4: Estimated energy demand for the whole building.

Highly insulated buildings such as this one require little heating and the internal gains play a significant role4 in maintaining the internal air temperature. The use of electrical appliances is a significant source of heat and the amount of electricity consumption can vary significantly. Richardson et al. (2010), for example, observed a tenfold difference in electricity use between the same type of properties. The results from 24 annual simulations are plotted in Figure 5. Each point in the graph is the summation of the heating demand for varying electrical loads and for four DHW drawoff cases, 0.0litres/person/day to 120.0litres/person/day. The four lines represent the different the space heating demand with the different DHW cases. The affect of the increasing electrical load on the annual heating demand can be seen as a reduction in heating. The BREDEM value of 20.6MWh electrical demand and 19.1MWh heat demand is indicated with the black dot. 


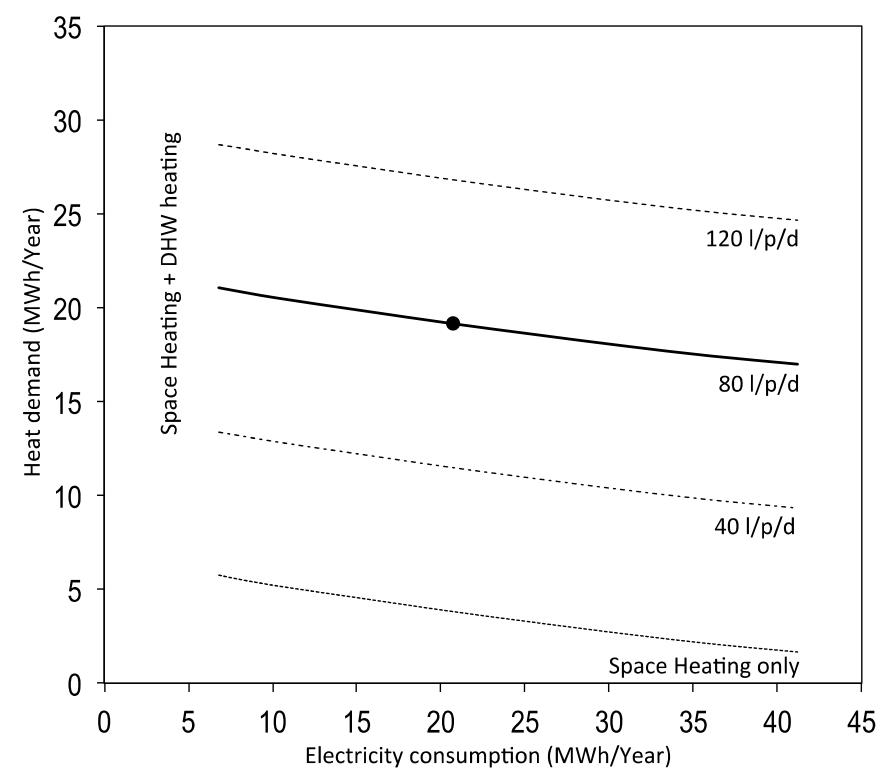

Figure 5: Annual thermal energy demand in relation to the annual electrical demand.

\section{Heat and electricity generation characteristics}

Since both electrical and heating energy can be generated on the roof, it is useful to look at the trade off characteristics between PV and STC. The electrical generation of the PV is taken to be proportional to the array area and the simulation confirms the findings of the literature, in that each $\mathrm{kWp}$ installed on the roof generates around $750-800 \mathrm{kWh}$ per year for this location. The pitch of the roof is low, only $6^{\circ}$ and hence for this building, only $741 \mathrm{kWh}$ is generated for every $\mathrm{kWp}$ installed.

The variation of the heat output of the STC is a function of roof area and the collector inlet temperature, which is dependant on the temperature coming from bottom node of the thermal stores. The relationships in Figure 6 are similar to those published by Brinkworth (2001) who derived a set of plots using the storage capacity and the collector area as variables. The left hand plot depicts the results of 12 simulations with varying STC area and DHW draw-off, since the rate of water draw has an impact on the energy stored. The higher use of DHW empties the thermal store allowing the heat to be replenished, hence increasing the yield from the STC. 

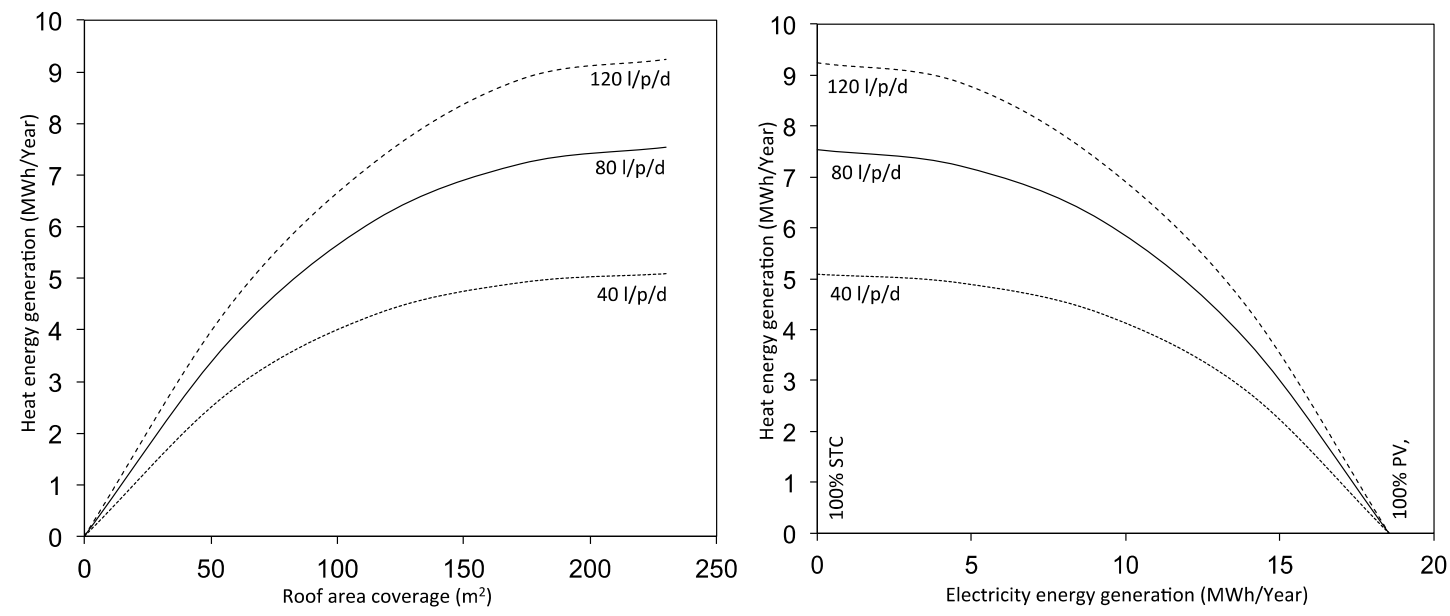

Figure 6: Yield of solar thermal as function of roof coverage and DHW draw (left) and the electricity to heat, roof generation trade-off characteristics (right).

A further 12 simulations were run varying the ratio of area covered by the PV arrays and the STCs on the roof from $0 \% \mathrm{PV}, 100 \%$ STC to $100 \% \mathrm{PV}, 0 \%$ STC. The right hand side of Figure 6 depicts the electricity to heat trade-off characteristic generated for this building. Note from Figure 5 that the annual BREDAM based estimates of electricity and heat consumption are 20.6MWh and $19.1 \mathrm{MWh}$ respectively. If the whole roof were covered with PV, the yield would be around $18.5 \mathrm{MWh}$, or $\sim 90 \%$ of the electrical demand of the building, as shown in Figure 6. The main observation is that neither PV nor STC can supply $100 \%$ of the electricity and heat demand, even when $100 \%$ of the roof is covered with one or the other technology and so additional lowcarbon heat and electricity generation is required.

Simulations were run to generate the seasonal performance of the high and standard performance air source heat pump over a number of operating strategies. The seasonal performance was calculated by,

$$
S P F=\frac{\sum E_{\text {thermal }}}{T_{\text {running }} P_{\text {in }}}
$$


where SPF is the Seasonal Performance Factor (- ), $E_{\text {thermal }}$ is the heat output of the heat pump at every time step in the run period $(\mathrm{kWh}), T_{\text {running }}$ is the time that the heat pump is running (hrs) and $P_{\text {in }}$ is the electrical input power $(\mathrm{kW})$. As part of the analysis, a number of HP scenarios were run to explore the variation in seasonal performance factors that could be expected in operation. Both standard and high performance HPs were run with the condenser water flow temperature set to $55^{\circ} \mathrm{C}$ and $65^{\circ} \mathrm{C}$. The flow temperature from the condenser impacts on the heat that can be exported to the thermal store, which is dependant on the temperature of the store. Decreasing the temperature of hot water supply increases the SPF of the HP, hence reducing the electrical energy required to generate the thermal energy. In addition, if the heat pump is not needed all year for heat production, i.e. used in combination with STC or a micro-CHP, then its operation could be restricted to those times when it is at its most efficient for generating DHW; i.e. during the warmer months of the year.

The calculated seasonal performance factors are summarised in Table 2. There is a significant range of SPF from 1.64 to 3.82. Making use of the higher SPFs is only likely if the configuration of the plant does not need the HP running during the colder periods. Replacing the heat pump with a better performing type will increase the performance, however, the improvement is not as large as reducing the flow temperature set point to $55^{\circ} \mathrm{C}$. Figure 7 plots the two bounding cases from Table 2, shown with the negative gradient on the left hand side. The length of the vector defines how much energy is converted from electricity to heat and is proportional to the number of running hours. The values on the $x$ axis and $y$ axis are the electricity and heat generated, respectively. 
Table 2. SPF for a standard and high performance heat pump with two water flow temperature set points for a range of operational strategies

\begin{tabular}{ccccc}
\hline \multirow{2}{*}{$\begin{array}{c}\text { Sunning period } \\
\text { Restricted to: }\end{array}$} & Standard & Standard & High Perform. & High Perform. \\
\cline { 2 - 4 } & $65^{\circ} \mathrm{C}$ & $55^{\circ} \mathrm{C}$ & $65^{\circ} \mathrm{C}$ & $55^{\circ} \mathrm{C}$ \\
\hline Whole year & 1.64 & 2.33 & 1.89 & 2.66 \\
Mar - Nov & 1.68 & 2.58 & 2.09 & 3.01 \\
Apr - Oct & 1.72 & 2.78 & 2.28 & 3.33 \\
Jun - Aug & 2.10 & 3.15 & 2.59 & 3.82 \\
\hline
\end{tabular}

On the right hand side of Figure 7 is also plotted similar electricity/heat characteristics for two different types of micro-CHP. The CHP converts (in this case) vegetable oil into both thermal and electrical energy, the ratio of which is determined by the plant. The limiting cases here are taken to be $1: 1$ to $10: 1$ (heat to electricity). Again, the length of the vector is proportional to the number of running hours and is also proportional to the amount of vegetable oil used. Note that since a gas boiler, bio-mass boiler or STC do not generate any electricity, they would be represented by a vertical line extending upwards along $x=0$ from the origin of the plot to the appropriate value of annual heat generation: PV extends horizontally rightwards along $y=0$, to the appropriate value of annual electricity generation since it does not produce heat. 


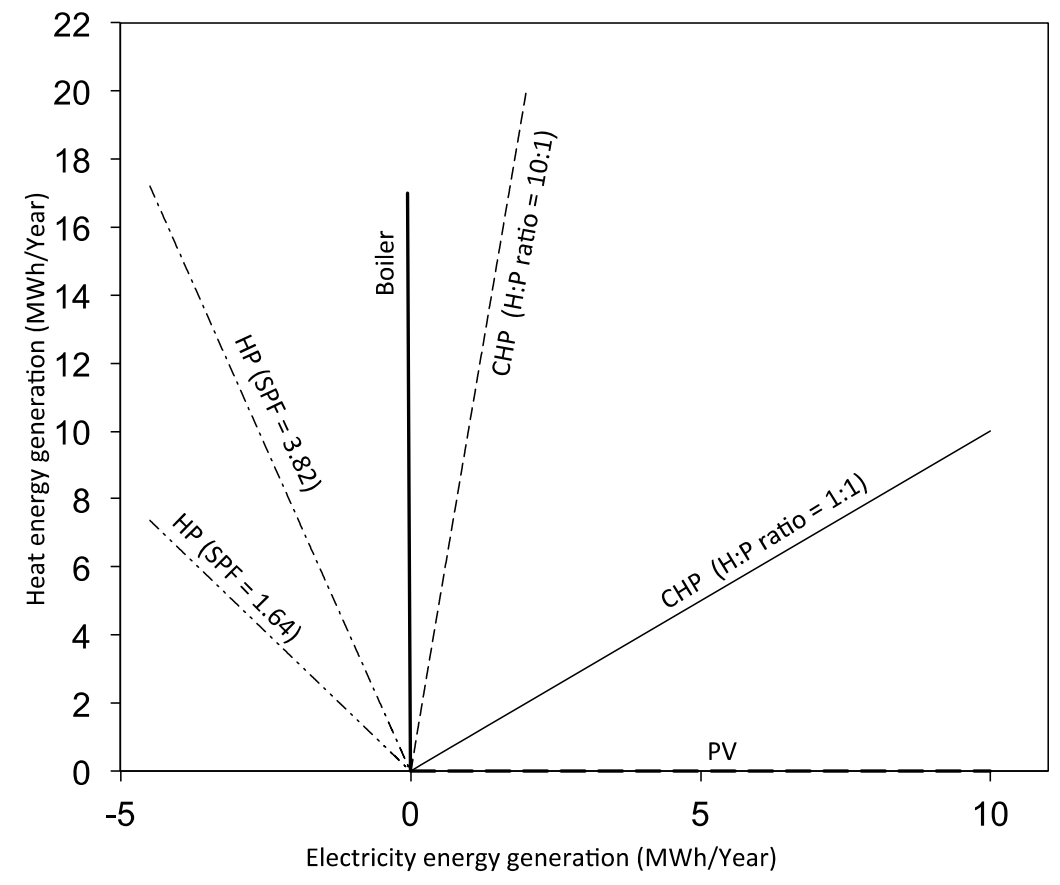

Figure 7: Thermal generation as a function of electrical power consumption/production with different type of generation plant.

\section{Heat and electricity generation options}

The heat/electricity generation characteristics depicted for the generation equipment in Figures 6 and 7 can be used in isolation, or in combination to determine the annual total building $\mathrm{CO}_{2}$ emissions (tonnes $\mathrm{CO}_{2} /$ year), $\phi$,

$$
\phi=\Delta \varepsilon \phi_{\text {grid }}+\frac{\Delta \theta \phi_{\text {gas }}}{\eta_{\text {boiler }}}+\frac{\tau_{c h p} \mu_{\text {chp }} \phi_{\text {veg_oil }}}{\eta_{\text {boiler }}}
$$

where $\Delta \varepsilon=\varepsilon_{g e n}-\varepsilon_{d e m}$, the difference between the annual generation of electricity and the annual electricity demand (MWh/year) and $\phi_{\text {grid }}$ is the carbon intensity factor for grid electricity $\left(\mathrm{kg} \mathrm{CO}_{2} / \mathrm{kWh}\right)$. If the installed generation equipment does not produce the electricity required, grid electricity is used to make up the difference. Conversely if there is a surplus of electricity generated, the carbon emissions from the buildings will be negative, indicating an offsetting of carbon generated by the grid. $\Delta \theta=\theta_{g e n}-\theta_{d e m}$ is 
the difference between the annual generation of and demand for heat in $\mathrm{MWh} / \mathrm{year}$ and $\phi_{\text {gas }}$ is the carbon intensity factor for natural gas. Surplus heat generated is dumped and hence a waste of energy. If the generation equipment does not produce sufficient heat it is assumed that this is achieved by burning natural gas in a conventional boiler plant. The energy demand is factored by the boiler efficiency, $\eta_{b o i l e r}$. Finally, if low carbon generation devices are used such as CHP or biomass boilers, the release of $\mathrm{CO}_{2}$ from the fuel must also be considered. In this case only CHP has been considered in the analysis and hence $\tau_{c h p}$ and $\mu_{c h p}$ give the run time (hrs) and the fuel consumption $\left(\mathrm{m}^{3} / \mathrm{hr}\right)$ and again factored by the efficiency $\left(\eta_{c h p}\right)$ and the carbon intensity factor $\phi_{c h p}$. In order to achieve true zero carbon performance, the over production of electricity and subsequent net export to the grid is required in order to offset the emissions from the combustion of vegetable oil with the relatively higher emissions of the grid generated electricity. The conversion factors for grid electricity, gas conversion and waste vegetable oil are taken from (Department for Environment, Food and Rural Affairs 2011) and given in Table 3.

Table 3: Carbon intensity factors $(\varphi)$ for electricity and heat generation. 
$\Delta \varepsilon$ and $\Delta \theta$ are derived from characteristic plots that depict the annual generation characteristics of the equipment. These have been derived from the simulation and hence implicitly represent any operational characteristics that are due to control setpoints and strategies, capacities, etc. Figure 8 shows two plots: the left with the high performance $\mathrm{HP}$, running all year with a water flow temperature of $55^{\circ} \mathrm{C}$; and the $\mathrm{CHP}$ characteristic lines for the 1:1 heat to power generation plotted. The right plot details the STC/PV trade-off curve from Figure 6 for the BREDAM case of 80litres/person/day DHW draw-off. On both plots is plotted the target (BREDAM) heat/electricity demand indicated by the large black dot: this is the target value, if the generation line crosses through the demand point there is no over or under generation and the demand is satisfied. The CHP in the first plot demonstrates that the CHP alone when run for 2350hrs can satisfy the electrical demand, but with a $\sim 1.4 \mathrm{MWh} /$ year over production of heat. The HP uses electricity to generate heat and requires $\sim 8.2 \mathrm{MWh} /$ year in addition to the $20.6 \mathrm{MWh} /$ year required to satisfy the electrical demand from appliances. The right hand plot demonstrates that on this building the limited roof space means that the target demand for electricity and heat cannot be met with either PV or STC.
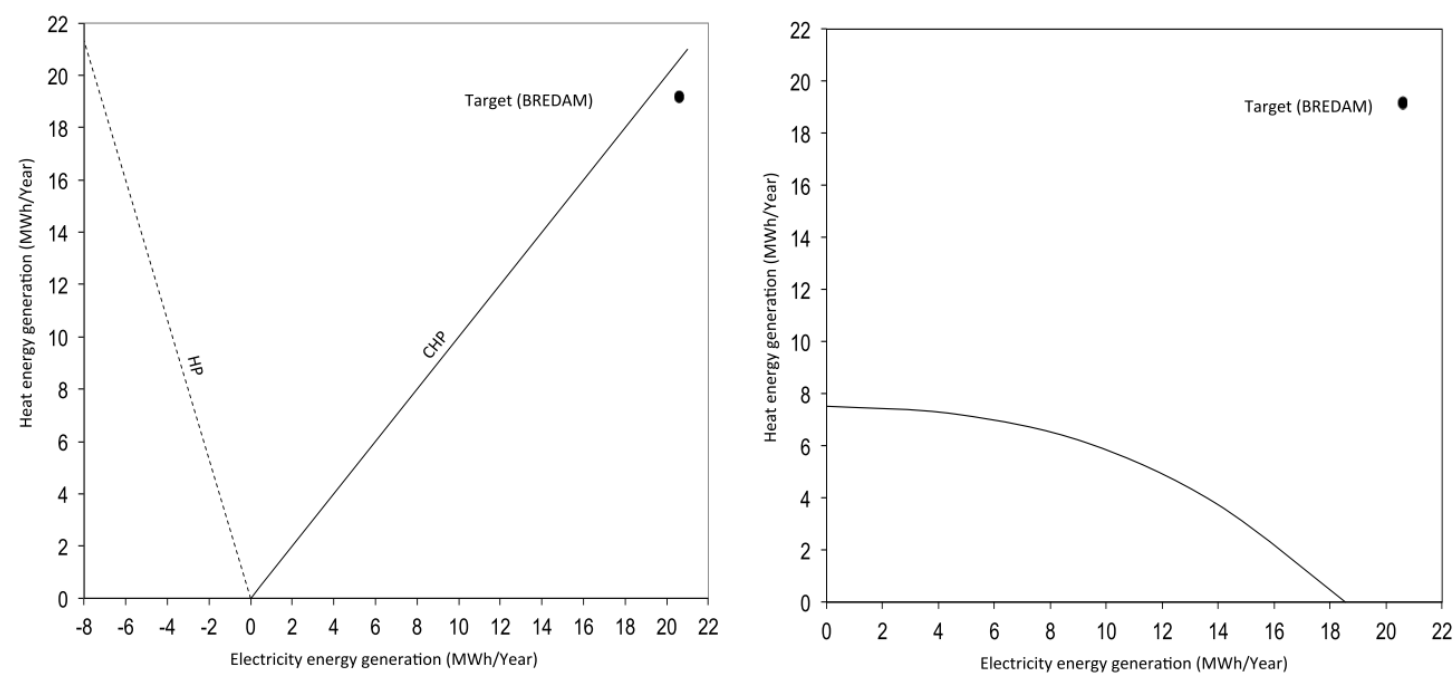

Figure 8: Single and roof generation demand deficit characteristics. 
This way of representing the analysis can be extended to include multiple generation devices. Figure 9 depicts the characteristics of a number of combinations of equipment and the resultant generation demand deficit.
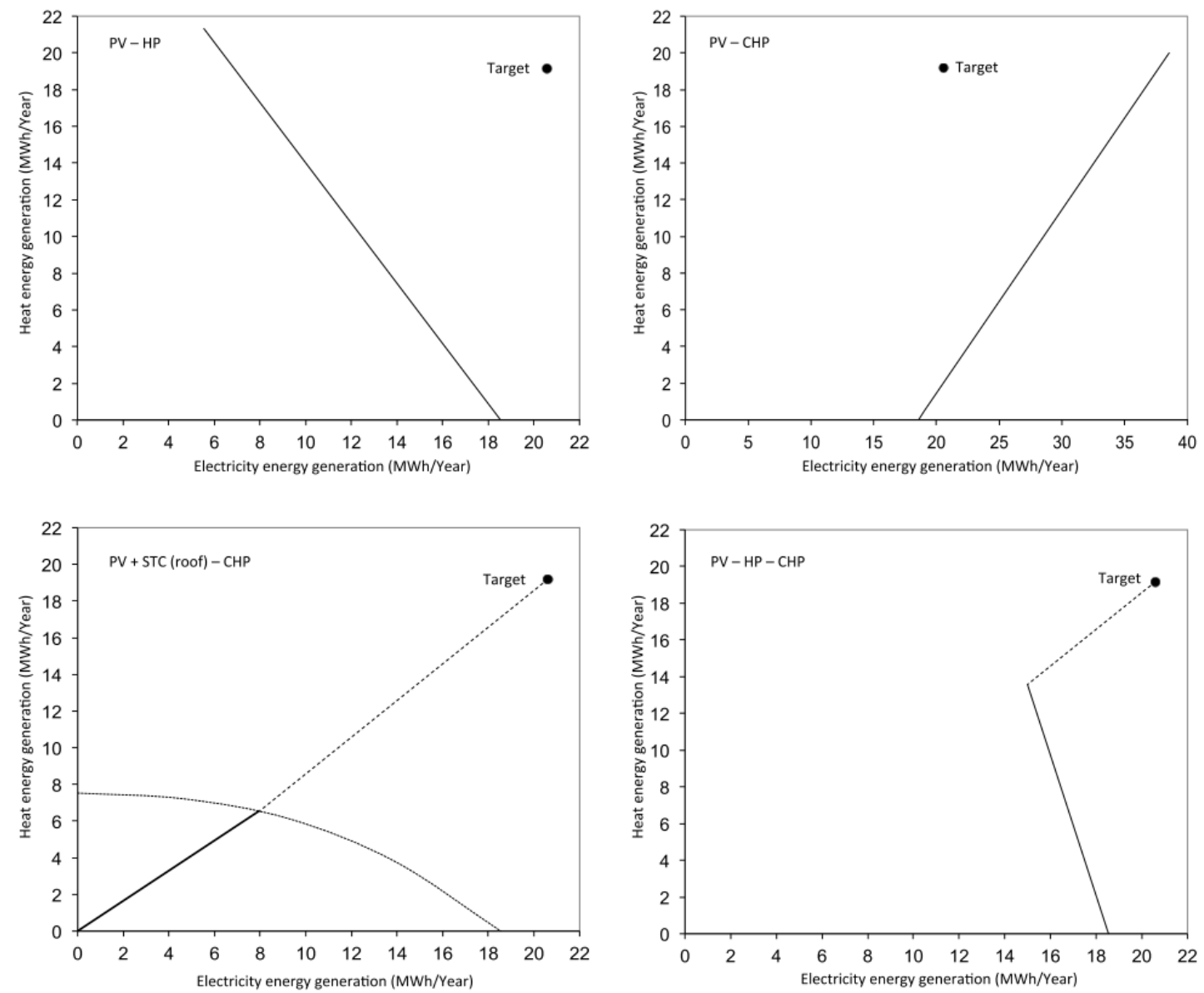

Figure 9: Multiple generation demand deficit characteristics.

Figure 9 depicts four plant combinations. The top two plots show two, two-technology options, PV and HP and PV and CHP and both configurations utilise a 100\% of the roof area covered with $\mathrm{PV}$. The former option has a generation deficit $\Delta \varepsilon=13.7 \mathrm{MWh} / \mathrm{year}$, while the latter option has a heat generation deficit $\Delta \theta=17.1 \mathrm{MWh} /$ year, although the CHP can be run for longer to deliver the required heat and provide a surplus of $\Delta \varepsilon=-27.1 \mathrm{MWh} /$ year electrical energy, which may be desirable, depending on feed in tariffs. 
The bottom two plots in Figure 9 depict three-technology options. The option on the left uses a combination of PV and STC on the roof the balance of which is determined by the selection of the CHP. In the plot the dotted line mirrors the relationship between PV and STC yield in Figure 6. The solid line represents the combined heat/electricity generation from the roof-installed technologies. The dashed line depicts the CHP generation. Here a CHP with a heat:power ratio of 1:1 has been selected, which determines the gradient of the dashed line. Following this line down from the target intersects the PV/STC characteristic line, determining the appropriate balance of roof generation technologies to be $44 \%$ PV and $56 \%$ STC. The length of the dashed line represents the CHP running time and hence the quantity of fuel used: this line is shorter than the CHP lines in the top right plot and in the bottom left plot, reflecting the reduction in vegetable oil used.

The last plot in Figure 9 shows the second of the three-technology options. The additional PV on the roof, a $100 \%$ in this option, is used to offset the power required for the heat pumps shown by the solid line. The dashed line shows the additional heat and electricity generation provided by the CHP, producing 5.6MWh/year of heat and the same of electricity. The reduction of the CHP run time between this option and the former option is due to the additional heat generated by the HP and this significantly reduces the vegetable oil required and hence the $\mathrm{CO}_{2}$ produced. The bottom right option depicted in Figure 9 is the least carbon intense configuration possible for this building. Expanding the generation equipment combination options, Table 4 details the balance of heat and electricity generation and demand for each of these and gives the annual $\mathrm{CO}_{2}$ produced in each case. A value of $100 \%$ shows that all of the thermal or electrical demand is met by the onsite energy system, a value of $0 \%$ shows that none of the thermal or electrical demand is met. A negative value shows that the configuration 
increased the electricity demand required (i.e. to power a HP). A value greater than $100 \%$ shows a surplus generated: Electricity is exported to the Grid, but Heat is assumed to be dumped to atmosphere, the $\mathrm{CO}_{2}$ emissions, however, are added to the total. Overruns of plant to achieve the production of electricity while dumping heat or vice-versa is not considered in this analysis, although is a viable option.

Table 4: Summary of onsite thermal and electricity generation options for the SHINE-ZC building.

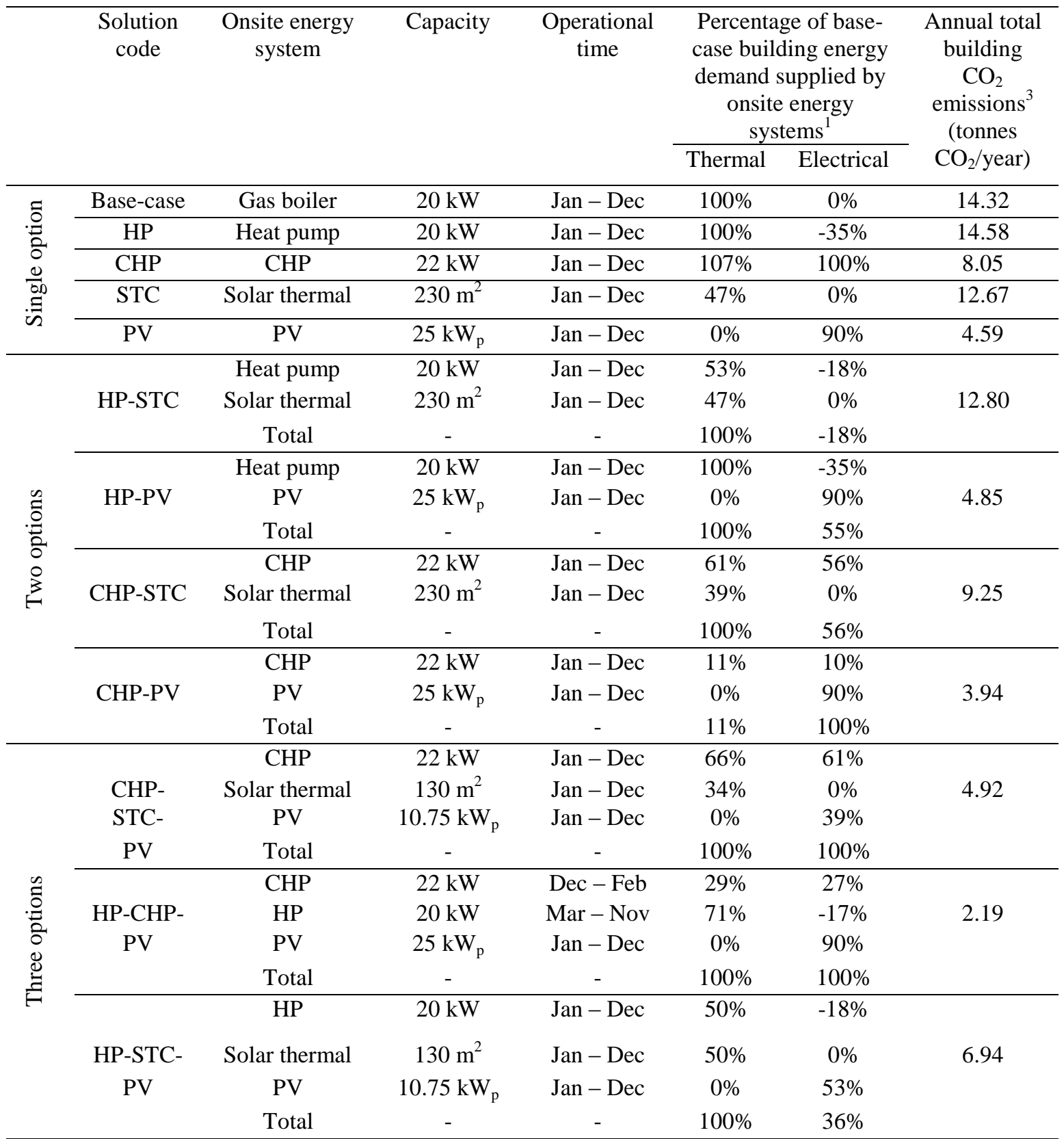




\section{Conclusions}

The zero-carbon performance targets set out in the CSH have been discussed in relation to compact-urban dwellings and a case study building has been presented. For the building reported here, generation options produce less than 5 tonnes of $\mathrm{CO}_{2} /$ year and the best of these produces 2.19 tonnes of $\mathrm{CO}_{2}$ /year and uses $\sim 1600$ litres of vegetable oil. To put this into perspective, fulfilling the complete requirement using the electrical grid and a condensing gas boiler would emit 14.3 tonnes of $\mathrm{CO}_{2} /$ year and the additional application of PV covering the roof completely would reduce this to 4.59 tonnes/year. These solutions are purely on the $\mathrm{CO}_{2}$ emissions, other criteria, like cost, environmental factors like air quality and noise, practicality has to be considered for a final solution.

The nature of compact urban dwellings often results in a number of constraints, all of which hamper achieving zero-carbon energy performance:

- shading, roof pitch and orientation;

- the roof area available for the collection of solar energy;

- the space available for heat and fuel storage; and

- the space available for the generation technologies.

The limited roof area results in the need to supplement heat and electricity generation with the application of low-carbon technologies, such as micro-CHP. It has been demonstrated that zero-carbon performance is not possible given the assumptions used in the simulation reported here and to achieve the net-annual heat and electricity production on site, the import of electrical and/or thermal energy is very likely. Also highlighted is that the $\mathrm{CSH}$ has a lack of guidance on the most appropriate energy consumption criteria to apply to estimating the in-use performance at the design stage, 
which is critical if these new developments are to contribute to the national reduction in $\mathrm{CO}_{2}$ emissions. Incorporating into the Code for Sustainable Homes in the U.K. the set points and estimations from the BREDEM model will give a handle on the thermal and electrical requirements for zero-carbon dwellings.

\section{Acknowledgements}

The approach was developed as part of the systems engineering doctorate program at Loughborough University in partnership with EMRE Ltd., a small to medium sized enterprise who designed the engineering services and managed the development.

\section{References}

Allen S.R. and Hammond G.P., 2010. Thermodynamic and carbon analyses of microgenerators for UK households. Energy 35 2223-2234

Allen S.R., Hammond G.P. and McManus M.C., 2009. Prospects for and barriers to domestic micro-generation: a United Kingdom perspective. Applied Energy 85 528-544 Anderson B.R. et al., 2001. BREDEM-8 Model Description. Available from: http://products.ihs.com/cis/Doc.aspx?AuthCode=\&DocNum=255441 [Accessed 25 August 2010]

Bahaj A.S. and James P.A.B., 2007. Urban energy generation: The added value of photovoltaics in social housing. Renewable and Sustainable Energy Reviews 11 21212136

Banfill, P. F. G. and Peacock, A. D., 2007. Energy-efficient new housing - the UK reaches for Sustainability. Building Research \& Information, 35 (4), 426 - 436 Baxi-Dachs mini CHP, datasheet http://www.baxi.co.uk/docs/Baxi_Range_Guide.pdf accessed February 2012. 
Bayod-Rújula A.A., Ortego-Bielsa A. and Martínez-Gracia A., 2010. Photovoltaics on flat roofs: Energy considerations. Energy 36 1996-2010

BINAS, 1998. Informatieboek VWO/HAVO voor het onderwijs in

natuurwetenschappen. Wolters Noordhoff Groningen, ISBN 9001893775

Brinkworth B.J., 2001. Solar DHW system performance correlation revisited. Solar Energy 71 377-381

Compagnon R., 2004. Solar and daylight availability in the urban fabric. Energy and Buildings 36 321-328

Department for Communities and Local Government, 2006. 06 BD 04224. Code Level 6 - an illustrated example. In: Code for sustainable homes. Available from: http://www.communities.gov.uk

Department for Communities and Local Government, 2007. Household Estimates and Projections

Department for Communities and Local Government, 2008. Code for Sustainable Homes: Setting the standard in sustainability for new homes. Available from: [http://www.communities.gov.uk/documents/planningandbuilding/pdf/codesustainhome sstandard.pdf] [Accessed 18 July 2010]. Department for Environment, Food and Rural Affairs, 2011. 2011 Guidelines to Defra / DECC's GHG Conversion Factors for Company Reporting: Methodology Paper for Emission Factors. Publication PB13625. Available from: http://www.defra.gov.uk/publications/files/pb13625-emission-factor-methodologypaper-110905.pdf [Accessed 10 January 2012] Energy Saving Trust, 2004. CE69. Renewable energy sources for homes in urban environments 
Energy Saving Trust, 2008. CE292. Energy efficiency and the Code for Sustainable Homes - Levels 5 and 6

Gill, Z.M., Tierney M.J. Pegg, I.M. Allan N., 2011, Measured energy and water performance of an aspiring low energy/carbon affordable housing site in the UK, Energy and building 43 426-436

Huld T., Súri M., Dunlop E.D., 2008. Geographical Variation of the Conversion Efficiency of Crystalline Silicon Photovoltaic Modules in Europe. Progress in Photovoltaics: Research and Applications 16 595-607

Intergovernmental Panel on Climate Change, 2007. Fourth Assessment Report (AR4) Climate Change 2007: The Physical Science Basis, technical summary, Available from: http://www.ipcc.ch/pdf/assessment-report/ar4/wg1/ar4-wg1-ts.pdf [Accessed 31 January 2012] James P.A.B., Sissons M.F., Bradford J., Myers L.E., Bahaj A.S., Anwar A. and Green S., 2010. Implications of the UK field trial of building mounted horizontal axis microwindturbines. Energy Policy 38 6130-6144

Keirstead J., 2007. Behavioural responses to photovoltaic systems in the UK domestic sector. Energy Policy 35 4128-4141

Klein S.A. et al, 2007. “TRNSYS 16 a TraNsient System Simulation program Volume 1 Getting Started” Solar Energy Laboratory, University of Wisconsin-Madison Knoll and Wagenaar, 1994. Handboek Installatie techniek. ISSO. ISBN 90-9006977-1 Mahdavi A. and Doppelbauer E-M., 2010. A performance comparison of passive and low-energy buildings. Energy and Buildings 42 1314-1319 Martin C. and Watson M., 2001. Side by side testing of eight solar water heating systems. ETSU S/P3/00275/REP/2, DTI/Pub URN 01/1292 
McManus A., Gaterell M.R. and Coates L.E., 2010. The potential of the Code for Sustainable Homes to deliver genuine 'sustainable energy' in the UK social housing sector. Energy Policy 38 2013-2019

National Statistics, 2007. Household Estimates and Projections. Available from:

http://www.ons.gov.uk/ons/rel/family-demography/families-and-

households/2011/index.html [Accessed 31 January 2012]

Office of the Deputy Prime Minister, 2006. Building regulations 2000 L1A,

Conservation of fuel and power.

http://www.planningportal.gov.uk/uploads/br/BR_PDF_ADL1A_2006.pdf. Accessed February 2012

Ren H., Zhou W., Nakagami K., Gao W. and Wu Q., 2010. Feasibility assessment of introducing distributed energy resources in urban areas of China. Applied Thermal Engineering 30 2584-2593

Richardson I., Thomson M., Infield D. and Clifford C., 2010. Domestic electricity use: a high-resolution energy demand model. Energy and Buildings 42 1878-1887.

Segen, 2006. CHP XRGI 17D specification. Available from:

http://www.segen.co.uk/downloads/xrgi17uk.pdf [Accessed 10 August 2010]

Simon Foote Architects, December 2008. Plans sections and elevations

Sparn B., Hudon K., and Christensen D., 2011. Laboratory Performance Evaluation of Residential Integrated Heat Pump Water Heaters. Technical Report NREL/TP-550052635

Steemers K., 2003. Energy and the city: density, buildings and transport. Energy and Buildings 35 3-14 
Steijger L.A., Buswell R., Smedley V., Firth S.K. and Rowley P., 2010. An air source heat pump model for operation in cold humid environments. $8^{\text {th }}$ International conference on system simulation in buildings, 13-15 December 2010 Liege

Steijger L.A., Buswell R., Smedley V., Firth S.K. and Rowley P., 2010. An approach to visualising the operational mix of renewable generation technologies needed to achieve zero-carbon emissions from compact Urban dwellings. $1^{\text {st }}$ IBPSA-England conference on building performance simulation, 10-11 September 2012 Liege

Stern, 2007. Stern review on the economics of climate change. HM Treasury. Available from: http://www.hm-treasury.gov.uk/d/CLOSED_SHORT_executive_summary.pdf [Accessed 10 August 2010]

Taylor S., Peacock A., Banfill P. and Shao Li., 2010. Reduction of greenhouse gas emissions from UK hotels in 2030. Building and Environment 45 1389-1400 TESS-inc., 2010. TRNSYS. Available from: http://www.trnsys.com/ [Accessed 22 June 2010]

The chartered institute of building services engineers, 1986. CIBSE Guide. Vol. A, London, ISBN 0-900953 292

The Royal Commission on Environmental Pollution Energy, 2000. The changing climate. Available from: http://eeac.hscglab.nl/files/UK-

RCEP_ClimateChange Jun00.pdf [Accessed 31 January 2012]

Tian W., Wang Y., Ren J. and Zhu L., 2007. Effect of urban climate on building integrated photovoltaics performance. Energy Conversion and Management 48 1-8 Tippkoetter Bio-Genio datasheet: http://www.tippkoetter.de/pdfdocs/Tippkoetter_Techinf_Bio_Genio.pdf Accessed February. 2012 
UK Health and Safety executive, 2009. Controlling Legionella in nursing and residential care homes. Available from: http://www.hse.gov.uk/pubns/indg253.pdf [Accessed 19 April 2010]

Watson J., Sauter R., Bahaj B., James P., Myers L. and Wing R., 2008. Domestic microgeneration: Economic, regulatory and policy issues for the UK. Energy Policy 36 30953106

Whispergen datasheet, www.whispergen.com/main/achomesspecs_info/ accessed February 2012

Yao R. and Steemers K., 2005. A method of formulating energy load profile for domestic buildings in the UK. Energy and Buildings 37 663-671 